\title{
A REPRESENTAÇÃO DA IMAGEM DA MULHER NAS PERSONAGENS INFANTIS
}

\author{
LA REPRESENTACIÓN DE LA IMAGEN DE LA MUJER EN LOS PERSONAJES DE \\ LOS HIJOS
}

\author{
THE DEPICTION OF THE IMAGE OF THE WOMAN IN THE CHILDREN'S \\ CHARACTERS
}

\author{
Rosa Maria Maia Gouvêa ESTEVES ${ }^{1}$ \\ Amanda Ribeiro DUARTE ${ }^{2}$
}

RESUMO: Esta pesquisa apresenta um estudo sobre a percepção das crianças sobre algumas personagens infantis, por influência do que é divulgado na mídia, no tocante às princesas e aos elementos abordados nas produções, tanto cinematográficas quanto televisivas e até em outras meios digitais ou até físicos. Na investigação de campo foram levantados dados com as turmas de segundo e quinto ano do Ensino Fundamental de um colégio particular, situado nas dependências de uma Faculdade privada em Resende, Rio de Janeiro. Tomando por base os elementos pesquisados, foi evidenciada a importância que estes contos possuem, visto à diferença de visões, conforme a idade dos participantes, em que os mais experientes têm uma visão diferente quanto às heroínas dos contos infantis, em contraposição aos mais novos. Também emergiu da pesquisa a questão da atualização dos profissionais da educação, uma vez a sociedade está sempre em mudança e se faz necessário a construção de outras competências docentes para lidar com o novo.

PALAVRAS-CHAVE: Sociedade e mídia. Personagens infantis. Representação feminina.

RESUMEN: Esta investigación presenta un estudio sobre la percepción de los niños sobre algunos personajes infantiles, por la influencia de lo que se revela en los medios de comunicación, con respecto a las princesas y los elementos cubiertos en producciones, tanto cinematográficas como televisimas e incluso en Otros medios digitales o incluso físicos. En la investigación de campo, se recopilaron datos con las clases de segundo y quinto año de la escuela primaria de una escuela privada, ubicada en las instalaciones de un colegio privado en Resende, Río de Janeiro. Sobre la base de los elementos investigados, se evidenizó la importancia que estos cuentos poseen, vistos por la diferencia de visiones, de acuerdo con la edad de los participantes, en los que los más experimentados tienen una visión diferente de las heroínas de los cuentos infantiles, en Contraposición al más joven. También surgió de la investigación la cuestión de la actualización de los profesionales de la educación, una vez que la sociedad siempre está cambiando y es necesario construir otras competencias docentes para hacer frente a la nueva.

1 Associação Educacional Dom Bosco (AEDB), Resende - RJ - Brasil. Professora e Orientadora no Curso de Pedagogia AEDB. Doutora e Mestre em Educação. ORCID: 〈https://orcid.org/0000-0003-1488-8314>. E-mail: rosamag@globo.com

2 Associação Educacional Dom Bosco (AEDB), Resende - RJ - Brasil. Pedagoga e professora no Colégio de Aplicação da AEDB. ORCID <https://orcid.org/0000-0002-3798-9321>. E-mail: duartea476@ gmail.com

Temas em Educ. e Saúde, Araraquara, v. 15, n. 1, p. 46-71, jan./jun., 2019. e-ISSN 2526-3471. 
PALABRAS CLAVE: Sociedad y midia. Carácter infantil. Representación feminina.

ABSTRACT: This research presents a study about the children 's perception about some children's characters, influenced by what is disclosed in the media, about the princesses and elements covered in the productions, both cinematographic and television, and even in other digital or even physical media. In the field investigation data were collected with the second and fifth year classes of Elementary School of a private college, located in the dependencies of a private Faculty in Resende, Rio de Janeiro. Based on the elements researched, it was evidenced the importance that these stories have, given the difference of views, according to the age of the participants, in which the most experienced have a different view regarding the heroines of children's stories, as opposed to the younger ones. The question of updating education professionals also emerged from the research, since society is constantly changing and it is necessary to construct other teaching skills to deal with the new.

KEYWORDS: Society and media. Child character. Women's representation.

\section{Introdução}

É inevitável comentar o quanto a sociedade se modificou e evoluiu e continua se desenvolvendo em todos os aspectos, seja social, educacional, econômico ou cultural, e o quanto se faz necessário a adaptação a estas mudanças, para que se possa estar inserido de forma saudável neste mundo.

Observa-se que esta evolução é vista de forma desconfortável por alguns, que percebem a mudança como algo nocivo, que os tira da zona de conforto ou que traz perdas. Esta pesquisa apresenta um estudo sobre e como a mídia influencia as escolhas das pessoas, indica padrões de comportamento, valores e como o consumo é introduzido na sociedade, sem protocolo. Aborda-se como estas influências impactam as crianças.

O objetivo desta pesquisa intitulada "A Representação da Imagem da Mulher nas Personagens Infantis” foi perceber como as crianças se sentiam representadas, no universo construído pela mídia, por meio de desenhos, filmes e contos, entre outros, e como as professoras atuam na canalização de suas escolhas. O caminho teórico foi construído por meio de pesquisas realizadas em livros, artigos e revistas, dentro de uma abordagem qualitativa, com objetivos exploratórios, uma vez que os estudos são iniciais.

A metodologia utilizada foi o estudo de caso exploratório, que consistiu em reunir informações detalhadas de um determinado problema, centrada na dinâmica do contexto para elucidar o que se desejava, com revisão de literatura e aplicação de entrevistas e desenhos. 
Na revisão teórica foi apresentada a história da infância e como se dá a construção da imagem das crianças, difundida pela literatura contemporânea, pelo cinema, vídeos, brinquedos, trazendo uma mensagem diferenciada dos contos clássicos, em que as crianças possam realmente se sentir parte da história e ter outras opções de escolhas, serem protagonistas, não somente serem retratadas, pelo o que é imposto ao seu gênero.

Ainda, se relata a evolução da mídia, como também das personagens de desenhos animados e o quanto esse conteúdo vem trazendo mudanças excepcionais para a aceitação de novos padrões que estão surgindo, representados por etnias e gêneros e o quanto se sentem importantes por estarem representadas por personagens nas telas do cinema e da TV.

A introdução destas novas personagens que superam o paradigma tradicional tem feito com que as meninas tenham um outro papel na sociedade, entendendo, reivindicando e pondo em prática seus direitos. Para Moscovici (1978) e Jodelet (1986), esse fenômeno chama-se representação social e é de fato importantíssimo que as personagens passem a representar todos os tipos de pessoas e que elas não tenham que se esconder atrás de um só padrão, tomando-o como certo, pois seria sua única opção.

Também é abordada a valorização destas novas personagens femininas, que trazem outras características, saindo de uma posição passiva para uma atuação presente e que tomam para si um papel na sociedade, dizendo que podem contribuir na construção de um ambiente familiar amoroso e na melhoria do seu entorno.

\section{Historiando e conceituando}

É notório que cada vez mais, que as personagens clássicas como Rapunzel, Cinderela e Branca de Neve estejam saindo de moda e dando lugar às personagens consideradas rebeldes por não seguirem padrões estéticos ou sociais desta sociedade contemporânea.

Desde o ano de 1998, as produtoras de desenhos infantis como a Disney vêm produzindo esse tipo de desenho com personagens mais libertárias. Com a saída das personagens clássicas surge uma nova classe de personagens, aquelas que como Mulan, que fingiu ser um homem para que seu pai não fosse à guerra, como Valente que luta para ter suas vontades respeitadas e contra um casamento obrigatório e Mulher Maravilha, uma das primeiras mulheres inseridas nos quadrinhos como heroína, fugindo daquele padrão de personagens femininas, no segundo plano

Essa nova classe de personagens vem também para ajudar as meninas a lidarem com o egocentrismo que as personagens clássicas passavam em seus filmes, colocando sempre a sua 
felicidade em primeiro lugar, sendo que atualmente, a proposta é trabalhar o incentivo ao altruísmo.

Com as personagens humanitaristas, os contos atuais têm chamado mais a atenção de meninas de todas as idades para esse universo que está cada vez mais próximo dos sentimentos reais, como proteção à família e o afastamento da idealização do casamento com o príncipe encantado, a proteção de si mesma e saber se impor perante a um problema. Hoje pode-se encontrar meninas, que querem ser enfermeiras como suas mães, porque ela salva vidas todos os dias. Muitas vezes, indagadas sobre o motivo de não quererem ser uma personagem como a Cinderela, relatam que a Cinderela é linda, mas nunca "faz nada para os outros, está sempre esperando que algo aconteça”, esta fala aponta que personagens passivas estão dando lugar às personagens ativas.

Então, este passivismo é interrompido por uma nova era de personagens que querem passar outro tipo de informação a quem as assiste. Desejam fazer com que as meninas entendam que nem tudo o que lhes é imposto, deve ser seguindo.

Para esclarecer este universo, apropria-se sobre a história da infância Ariès (1973) percebe que no começo da década de sessenta, a história da infância e a história da educação pareciam ser dois campos distintos e inconciliáveis de pesquisa, até então, poucos foram os pesquisadores que se dedicaram a um estudo aprofundado sobre a evolução da criança na sociedade e como esta passou realmente a ser conhecida e considerada como objeto de estudo. Para Ariès (1973) e De Mause (1991) a história da infância e o seu desenvolvimento já faziam parte consideravelmente da evolução da humanidade, e as crianças, então, passaram ser reconhecida como membro da sociedade, respeitadas em todos os seus aspectos.

A falta de pesquisas e estudos sobre crianças na antiguidade, reflete sua desvalorização na perspectiva histórica, ao ignorar o desenvolvimento da fase inicial da vida do ser humano, por consequência ignora-se a infância, como período das primeiras descobertas. Narodowski (1993) afirma que a infância faz parte da história, entendida como um "fenômeno histórico" e não somente um fenômeno natural. $\mathrm{O}$ autor afirma que existe uma heteronomia. A criança obedece ao adulto, e em troca o adulto deveria proteger a criança, portanto, o infante não tinha poder algum diante das situações ocorridas em casa ou no seu meio social. Estava sempre submetido à tutoria de um responsável.

A história carrega esta "falta de atenção" para com as crianças, que não tinham um empoderamento social, eram desprovidas de direitos e da participação de reuniões familiares, 
de tomada de decisões, das festas e do convívio social, desta forma não tinham vez, nem voz e consequentemente excluídas da vida cotidiana.

Ariès (1973) esclarece que na Idade Média, as crianças acompanhavam os adultos, compartilhando o mesmo lugar e dividindo situações. A sociedade medieval era pouco adaptada às crianças, não havendo divisão de idade para trabalhos e principalmente aquele sentimento de infância, em que a criança tem por direito de se desenvolver, brincar, sonhar e educar-se. Sua aprendizagem era voltada para os trabalhos braçais, e os adultos presentes naquela sociedade acreditavam que o importante era ensinar a criança para que crescesse como um adulto forte, com suas funções sociais, já pré-estabelecidas, como a caça, os trabalhos mais pesados como marcenaria para os meninos e o cuidado da casa e dos filhos para as meninas.

De Mause (1991) demonstra que a criança era considerada um ser irracional e, portanto, acreditava-se que a criança era incapaz de agir com propriedade, dentro das experiências da sua idade, perante à sociedade. Conclui-se, então, que a primeira preocupação com a infância foi sobre a disciplina, limitando todo e qualquer movimento destinado ao prazer e ao aprendizado.

Levin (1997) entende que no século XVII, surge a concepção real da infância, a partir da observação de que crianças muito pequenas precisavam de atenção e cuidado dos adultos. $\mathrm{O}$ adulto passou, então, a entender que deveria se preocupar com a criança com o seu desenvolvimento, enquanto ser dependente e frágil. Fato este, que ligou esta etapa da vida a ideia de proteção.

Ao analisar o conceito de infância, ele se multiplica de várias formas. Desde o começo deste reconhecimento da criança como ser ativo e passivo da sociedade até hoje, as crianças vem tomando seu lugar, que fica cada vez mais importante ao pensar em desenvolvimento futuro. Sempre reconhecidos como "o futuro do país", essa valorização faz com que estudos continuem acontecendo, mesmo sem ter um conceito exato, para que a infância seja cada vez mais valorizada e melhor entendida.

Outro aspecto importante a se destacar sobre infância é o fato de que o lúdico tem ganho um papel relevante no desenvolvimento das crianças, sendo uma forma atrativa para desinibir e cativar a participação das crianças na aquisição do conhecimento, de forma produtiva e agradável e uma dessas formas é sem dúvida a literatura.

\section{A introdução da literatura}

Com o desenvolvimento da humanidade e a aceitação e a percepção de que a criança realmente tinha valor, a atenção voltou-se para ela, de forma que a educação fosse o principal 
canal para difusão de cultura e ensinamentos relativos à educação Infantil. A literatura passou a ser uma aliada dos pesquisadores e educadores, fazendo com que as crianças aprendessem a ler e a associar o mundo imaginário e lúdico com a sua realidade social, contribuindo para o seu desenvolvimento.

Se antigamente as histórias eram contadas somente pelos pais e avós na cabeceira da cama ou ao redor de uma fogueira, hoje, o contador se tornou uma profissão e está presente nas escolas, shoppings, praças, hospitais e feiras. A essência de narrar não mudou, mas muitos grupos se valem de outras técnicas como o teatro, os bonecos e a música para dar uma incrementada nas fábulas, contos e lendas (TEIXEIRA, 2010, p. 56).

Como cita Teixeira (2010), o contador de histórias é tão antigo quanto o fato delas existirem. Antigamente, as histórias eram passadas somente pelos pais e avós, em que suas falas se tornavam verdades absolutas para quem as escutava. Desta forma, eram tomadas como um rito, fazendo com que lendas e fábulas se tornassem realidade na mente do ouvinte, já que eram passadas por pessoas do mesmo ciclo social.

As histórias repassadas por seus contadores tomavam diferentes formas e continuidades na cabeça dos próximos ouvintes, que assim davam continuidade a seu ciclo e com mais frequência, principalmente, se levadas à sério e se tivessem um ensinamento no final, como as fábulas antigas da Tartaruga e da Lebre, da Cigarra e a Formiga, de Esopo que sempre continham uma lição de moral para ensinar às crianças sobre as regras sociais ou evitar o rompimento das mesmas.

Em meados do século XIX, afirma Teixeira (2010) não se contava com os recursos da tecnologia, fazendo com que as histórias fossem simples, levadas para que os ouvintes passassem a vivenciá-las como verdade, de certa forma fossem também criadas lições de moral e a implementação de valores à sociedade. Se um menino roubasse um pão em uma padaria, e o padeiro contasse a todos sobre o roubo, a reputação deste menino seria afetada, fazendo com que, em muitos casos, estas lições fossem tomadas como um exemplo a não ser seguido.

As histórias eram passadas oralmente, fazendo com que o ouvinte recorresse à imaginação, mas com o avanço da forma de como contar as histórias, assim, foram criados fantoches e dedoches (fantoches para os dedos) como artifícios para o contador de história, visando o encantamento do que se desejava comunicar. Na oralidade tinha a supremacia do conto, com a entonação e mudanças de vozes para encenar os personagens da história, características marcantes para dar alma as narrativas. 
As histórias eram um dos únicos artifícios de diversão e brincadeira para as crianças, fazendo com que a arte de interpretar fizesse parte da brincadeira, recheadas de fantasias e lições de moral. As narrativas não precisam ser oficiais, poderiam ser inventadas na hora, em estilo musical ou apenas para passar o tempo e instigar às crianças a trabalharem o lúdico ou como forma de entretenimento para os ouvintes.

Ainda na sociedade medieval, as crianças tinham pouca importância no desenvolvimento da sociedade, de forma que não faziam parte, nem de forma subliminar nas decisões tomadas pela casa. Seus sentimentos tampouco importavam, somente sua saúde e desenvolvimento para seguir o destino do pai, como caça e trabalho bruto. Vivia no meio dos adultos, só aprendendo atividades que realmente fossem agregar valor bruto a sua vida, como luta, pesca e cuidar de sua mulher e filhos, em caso de meninos. No caso de meninas, zelar pela casa e filhos.

\begin{abstract}
A passagem da criança pela família e pela sociedade era muito breve e muito insignificante. Ela era vista como substituível, como ser produtivo que tinha uma função utilitária para a sociedade, pois a partir dos sete anos de idade era inserida na vida adulta e se tornava útil na economia familiar. Realizando tarefas, imitando seus pais e suas mães, os acompanhava em seus ofícios, cumprindo, assim, seu papel perante a coletividade. A duração da infância era reduzida no período mais frágil, enquanto "filhote de homem" não podia cuidar de si sozinha (ROCHA, 2002, p. 25).
\end{abstract}

A partir do momento que a criança é considerada como cidadã, passa a ser ouvida, a se vestir de forma adequada, realizar atividades direcionadas a sua idade, brincar por mais tempo, com pessoas da sua idade, ter direitos respeitados e realizar atividades mais adequadas a ela. Surge a partir daí a preocupação da formação moral e social da criança. A família tornou-se um âmbito de carinho e amor, como referência da criança e de seu desenvolvimento motor e moral. Mesmo com cada criança se desenvolvendo no seu tempo, o respeito passa a ser obrigatoriedade perante às leis que agora também abrangeriam às crianças.

A criança passou a ser objeto de estudo, ganhando mais atenção e espaço perante à sociedade, sendo a protagonista maior de um ciclo reconhecido da vida: a infância. Seguindo o pressuposto de tanta relevância, a criança como protagonista da infância, faz com que a sociedade passe a dar mais importância às suas observações e forma de ver o mundo. Assim, a criança ganha voz, ganha um jeito de fazer parte da formação social dos seres humanos, emitindo informações e tendo sua opinião respeitada por todos aqueles, em diferentes ambientes. 
A literatura é de fato um caminho lúdico para se trabalhar e desenvolver as regras e participação das crianças, que se sentem mais representadas com essa nova leva de personagens femininas numa sociedade que vive em constante mudança.

De fato, a literatura é um dos primeiros contatos que as crianças têm com a escrita. Assim, ela vem se desenvolvendo cada vez mais para que esse crescimento positivo seja muito produtivo. Hoje em dia, podemos encontrar diversos tipos de literatura escrita, cantada, entre outras e este fato faz com que a literatura tenha uma gama de opções para agradar a cada um.

Mesmo com a chegada de outras mídias, a literatura ainda cumpre o seu papel principal; ser a grande aliada da educação. Ela também se ajusta com o tempo, para não ser tão monótona e cansativa, mas sim para agradar a todos os tipos de leitor.

Assim, a literatura hoje em dia continua sendo um artifício de suma importância para os professores, sendo um aliado para a educação e um grande fator de influência para as mídias.

\section{O poder da mídia e a sociedade}

A comunicação para o homem surge a partir da necessidade de autoproteção e evolução da espécie. Dessa forma, desde o começo desta comunicação, até os dias atuais a mídia é um veículo de informação entre telespectadores, emissoras, Internet e a forma rápida como a informação é passada ou pode ser acessada também evoluiu.

Hoje tem-se acesso rápido a qualquer tipo de informação que se procura, desde como saber a ortografia correta de uma palavra até acessar trabalhos acadêmicos confeccionados em outros países ou línguas, o que facilita muito a vida corrida atual. Esse avanço além de facilitar a vida, também nos remete a uma fase importante da sociedade, que a comunicação escrita, por exemplo, é fundamental.

Essa influência se dá pelas mídias atuais, onde as crianças têm acesso à informação muito mais rápido do que antigamente, possibilitando o entendimento mais frequente e sem rupturas na comunicação mídia-consumidor.

La Taille (2008) entende que a criança é mais suscetível a este meio de influência, já que não tem condições de discernir o que é saudável para ela, o que a torna o alvo de toda essa publicidade, ou seja, filmes voltados para as crianças as incentivam a serem como tais personagens que elas tenham gostado, baseando-se nas ideologias de quem está próximo, sejam os pais, família, escola ou etc.

Para Straubhaar e LaRose (2004) a alfabetização e a leitura começaram a afetar o comportamento das pessoas, o modo que agiam e como lidavam com certas situações. As 
pessoas alfabetizadas dependiam menos da memória para manter culturas, técnicas, histórias épicas, mitos e imagens na transmissão destas ideias de uma geração para outra. Assim, entende-se que as histórias passadas para as crianças eram o início de sua alfabetização, pela escuta potencial de cada uma dela e a associação de imagens às palavras.

Essa evolução da mídia também é encadeada por alguns fatores importantes que cercam a sociedade, como a evolução dos transportes e imprensas, a velocidade com que a informação chega a um local, a evolução da tecnologia em sua transmissão. Hoje, a facilidade de envio da informação, mesmo quando ocasiona rupturas na transmissão, está em níveis muito mais elevado e por vezes complexo, isto, é, dependendo como se quer comunicar em qual mídia em seus desdobramentos, podendo ter repercussões positivas ou negativas.

Sampaio (1984) afirma que depois da Segunda Guerra Mundial (1945) a mídia teve um grande avanço com o início do cinema, com a transmissão de rádio, em que se procurava adaptações da vida do povo americano, fazendo com que a mídia ganhasse mais telespectadores e trazendo maior audiência para programas de rádio e televisão. Os americanos se sentiam representados pela mídia televisiva, assim, ela começou a avançar.

Ainda sobre a influência da mídia, pode-se indagar com o seguinte questionamento: A mídia muda a sociedade ou a sociedade muda a mídia? Acredita-se que têm motivos suficientes para lhes mostrar que os dois caminham juntos, onde podemos acompanhar as mudanças diariamente, fortalecendo a ideia de que somos livres para termos escolhas diferentes dos outros e que escolher uma cor de roupa, por exemplo não nos torna uma pessoa ou nos coloca em um grupo, já que são estereótipos que estamos reforçando e mostrando o quanto precisamos desfazer esse tipo de ideia que vem acompanhada de preconceitos.

Hoje, a mídia vem se adaptando cada vez mais para incluir todo tipo de pessoa em seu marketing. Campanhas como "respeito ao próximo" e "valorização das culturas", por exemplo, tem feito bastante sucesso campanhas que rompem o estereótipos. Essa adaptação também ajuda na influência e desenvolvimento social, pois se a mídia começa a representar um certo grupo que antigamente não recebia tanta atenção, ele passa a ser reconhecido e isso acontece por que essa divulgação disponibiliza uma gama de representações sociais. Cada indivíduo se sente parte de uma sociedade sem segregação.

\section{Representações sociais}

As representações sociais, conforme Moscovici (1978) e Jodelet (1986), são fenômenos psicossociológicos, e são explicadas com base em implicações não só psicológicas como 
também sociais e ideológicas, o que as integra ao contexto das determinações históricas e culturais. A cultura, as trocas de informações e o processo de construção e reconstrução do cotidiano levam cada pessoa a desenvolver a sua ética pessoal para melhorar um coletivo, já que se vive em sociedade e deve-se respeitar leis e regras. E mesmo sendo um desenvolvimento individual pensado no coletivo, quem prestigia a ética do indivíduo é a sociedade na qual ele está inserido. Esse coletivo faz com que as pessoas desenvolvam continuamente para formar cidadãos melhores, com uma ética e educação mais firme possível.

A representação social é, portanto, uma forma de conhecimento do senso comum originário das trocas da vida cotidiana que, além de ser socialmente elaborado e compartilhado, tem um papel de extrema relevância na visão que os grupos sociais e seus indivíduos erigem sobre a realidade para transformála em familiar, constituindo em uma modalidade de saber prático orientado para a comunicação, o entendimento e o domínio do contexto social, material e ideal (SHIMIZU, 2018, p. 2).

Cada pessoa se identifica e se apropria com a sua representação social e utiliza essa representação com o grupo social ao qual ele pertence, o que leva a crer que a representação se diferencia conforme os conjuntos sociais que a elaboram. Assim, as crianças que se sentem representadas por heróis, influências da mídia, tendem a se comportarem como heróis em seus filmes, quando estão brincando ou quando precisam resolver situações do cotidiano, de forma que prefiram ser chamadas pelo nome da sua representação social, neste caso, o nome do herói que se identificam.

Desse modo, uma representação pode ser qualificada de social por suas funções de servir de exemplo para ações, orientações na relação dos indivíduos com o mundo e com os outros, e ser um fator de leitura da realidade, fornecendo códigos de comunicação e contribuindo para definir uma visão comum em relação a valores, desejos, necessidade e interesses dos grupos que a partilham.

Pierre-Puysegur e Corroyer (1987) se referem a representação social como um exemplo de família, educação, personalidade infantil e da mídia na construção social de cada criança, como se as crianças reproduzissem os diferentes grupos e modelos, tendo como mediadores a mídia e a ideologia. Assim, as crianças procuram sua representação social baseadas nas ideologias que elas, ou a família, ou as pessoas (professores, outros amigos e etc.) que a rodeiam acreditam.

Chombart de Lauwe (1986) possivelmente une a relação precisa entre os personagens apresentados diretamente às crianças pelos meios de comunicação e as representações sociais 
formadas em relação à essa exposição, que entende a transmissão social das representações, dos valores, e principalmente, do processo de socialização das crianças.

Entendendo que um estudo sobre a evolução das representações sociais da infância, realizado por meio de desenhos, desenhos animados e filmes, é uma ideia importante sobre a experiência real das crianças e as imagens que remetem os meios de comunicação de massa, que exercem uma influência relevante na socialização das crianças. Levantar os possíveis fatores de influência na construção das representações de moral das crianças, impactado pelos meios de comunicação, são sim uma influência para as representações sociais das crianças.

\section{Os produtos de consumo}

É inegável que a publicidade ajuda a vender qualquer produto, aumentando a sua porcentagem de lucro e incentivando mais consumidores a comprar por indução publicitária, por meio dos benefícios de adquirir tais produtos com a intenção de aumentar suas vendas e muitas vezes conquistar uma fatia do mercado.

Como exemplo, a maioria das empresas especializada em brinquedos voltadas para o mercado infantil, objetiva a elaboração de comerciais que criem necessidades para as crianças. Dessa forma, existe um aumento de sua visibilidade, exibem comerciais nos intervalos dos desenhos infantis, quando as crianças são os telespectadores, com efeitos coloridos, com músicas para que a atenção da criança seja totalmente, voltada para o meio de comunicação e que desperte o desejo de consumir aquele produto e consequente a compra do mesmo.

Como as propagandas para o público infantil costumam ser veiculadas pela mídia, e a mídia costuma ser vista como instituição de prestígio, é certo que seu poder de influência pode ser grande sobre as crianças. Logo, existe a tendência de a criança julgar que aquilo que mostram é realmente como é, e que aquilo que dizem ser sensacional, necessário, de valor, realmente possui essas qualidades (LA TAILLE, 2008, p. 13-14).

Sendo assim, as crianças são mais suscetíveis a esse tipo de propaganda, o que gera bastante lucro nesse mercado. É inevitável comentar sobre os filmes que também são produtos e possuem grande participação nesse mundo de consumo evidente, como os trailers, bonecos de filmes em lojas, até em baldes de pipocas contém a publicidade.

No universo infantil, onde o mais colorido, mais animado e com mais música é o que chama atenção, chega-se num ponto importante: as personagens. Alguns locais aproveitam para investir nessa publicidade, como lojas de fastfood, lojas de brinquedos que investem em brinquedos com lançamentos e personagens de grandes sucessos para atrair a atenção dos 
consumidores, fazendo com que esses personagens deixem de influenciar só nas telas, e passem a ser físicos também.

Essa publicidade faz crescer o número de consumidor do produto, que no caso é o personagem e isso aumenta a renda para eles, de forma que a mídia incite a venda de produtos relativos ao personagem e satisfaça o cliente, que procura pelo mesmo. Essa valorização é de fato boa para os dois lados. A empresa cria o personagem, a mídia o faz ficar conhecido e o consumidor que compra fica satisfeito com o que está consumindo.

\section{A Representação da Imagem da Mulher}

Um fator importante a comentar sobre a representação da imagem da mulher é que as personagens modernas rompem a barreira da cor rosa, somente para meninas, uma vez que a princesa Elsa do filme Frozen (2014) da Disney não contém detalhes rosa em sua roupa, sendo toda azul, o que nos mostra essa quebra do paradigma que define cor por gênero. Essa influência moderna pode ser notada nas crianças também quando elas desejam ser pessoas com empregos que ressaltam a importância da ajuda ao próximo, em que estas personagens não buscam mais pelo amor romântico e sim o amor que tenha resultado positivo, o amor ativo, que não há somente benefícios próprios, como a Mulher Maravilha (2017), que luta para o bem de sua aldeia.

Nesse sentido, o que se deve trabalhar numa pedagogia emancipatória de gênero? Tudo que possibilite a conscientização, a libertação e a transformação de suas realidades, entendendo que a partir deste tópico, as crianças podem se apoiar numa estratégia de superação e recuperação de alguns paradigmas criados pela sociedade para os gêneros, fazendo assim com que entendam e possibilitem de outras escolhas, tenham opiniões mais consistentes, defendendo suas ideias baseadas em critérios entendidos, e não inventados.

Perante todo esse impasse social e cultural, a cultura infantil como objeto de análise crítica nos fornece uma gama de oportunidades para que a criança se torne bastante importante nessa dimensão social. Essa não importância à cultura infantil reflete em maior parte quando se ignora o fato das personagens sempre serem postas em segundo lugar, o personagem masculino estar sempre acima delas e inocentemente as crianças são levadas a passividade, aprendem que a figura masculina está sempre acima da figura feminina e consequentemente são induzidas a aceitar essa imposição do segundo plano e deixar com que outros decidam onde é o lugar delas. 
Também é importante destacar que as crianças procuram nos filmes sobre personagens femininas, naquele mundo imaginário de segurança, coerência e inocência infantil um modo de segurança, onde esperam ter a certeza de que o "final feliz" e o "felizes para sempre" chegará certamente, afetando assim suas vidas emocionais. O que é diferente na realidade, sem graça e monótona da escolarização, então a literatura passa a ser muito utilizada para a sensibilização da vida das crianças já que num mundo imaginário, todos são livres e cada pessoa pode interpretar do seu jeito. Tudo é possível.

É necessário lembrar que essa mudança na sociedade acompanha o desenvolvimento e influência da mídia por meio social, trazendo o desenvolvimento da sociedade, como colocar a mulher como personagem principal de um filme que antigamente era somente lugar dos homens e fazer com que esse empoderamento seja também para as meninas e mulheres.

Thomaz Tadeu (1995) afirma que a Disney tem a imagem para alguns críticos como pouco mais que uma máscara promocional que oculta suas agressivas técnicas de marketing para educar as crianças para as virtudes de se tornarem consumidoras ativas. A grande maioria dos jovens e adultos cresceu vendo clássicos como Homem Aranha, X-Men, e os filmes de princesas da Disney e isso não termina por agora, os clássicos estão passando por melhorias, virando filmes com pessoas reais, saindo do desenho, porém a história muda pouco.

Essa questão abordada neste trabalho sobre a influência masculina acima e esse passivismo passado nos filmes, continua firmemente presente nestes filmes, questão essa que precisa cada vez mais ser mostrada e discutida pelos professores, já que a Disney é senão a maior, uma das maiores influenciadoras empresas de entretenimento infantil e jovem.

Essa influência se concretiza quando indago professores mais experientes sobre o assunto e eles relatam que essas personagens atuais trazem a violência e com que as meninas não ponham as vontades de suas famílias, não entendendo que a família só faria o melhor para seu desenvolvimento.

Crianças que entendem os assuntos abordados nesses tipos de filmes conseguem discernir o certo do errado, pensando em como melhorar a vida de suas famílias e não põem o amor romântico em primeiro lugar, e sim o amor ao próximo.

Desde pequenos, as crianças são rodeadas de literatura. Pois conhecem as grandes histórias na escola, como Menina Bonita do Laço de Fita, que conta a história de uma menina com o coelho que fala sobre as diferenças entre as pessoas. Como no livro que trata sobre uma menina que era diferente de todas as outras, no dia a dia pode-se encontrar meninas que estão entendendo mais o contexto dos contos e crescendo não somente como reprodutoras, mas sim 
como produtoras de cultura, fato esse que em algumas vezes são mal visto pela sociedade, que espera que as meninas cresçam para criar uma família ou casarem.

No livro "Diferentes, Não Desiguais" de autoria de Lins, Machado e Escoura (2016, p.56) indagam: "Se muitas mulheres sonham em ter filhos ou adoram se maquiar, será que não é porque desde pequenas elas foram ensinadas que "menina é vaidosa" e que "toda mulher deve querer ser mãe"? Será que muito do que somos não é aquilo que a sociedade nos ensinou e espera de nós?” Quando se insiste em repetir generalizações de gênero como essas em casa ou na escola, na televisão ou na rua, mostra-se que estereótipos estão certos. Termos como esses não são aceitáveis para se referir às meninas que estão compreendendo que possuem escolhas, por isso analisam o conto com mais enfoque na intenção real do que seguirem exemplos antiquados como a ideia de que mulher deve somente casar e ter filhos, cuidar da casa e do lar, sem poder trabalhar fora de casa.

Os livros contados desde pequenos para as crianças são os que marcam sua infância, portanto, a família deve sempre entender que é importante qual os tipos de leitura estão rodeados de seus filhos, pois eles os ajudarão a passar por diversas situações e servirão até como exemplos.

\section{Trajeto Metodológico da Pesquisa}

A metodologia empregada foi o estudo de caso, que segundo Yin (2005, p.32) "o estudo de caso é uma investigação empírica que investiga um fenômeno contemporâneo de seu contexto da vida real", isto é, linkado a questões do cotidiano. Foram percorridos os procedimentos para a coleta de dados, que segundo Mattar (2001), os dados de campo permite caracterizar os aspectos de um caso de estudo e que para tanto o pesquisador precisa tomar algumas providências: obter a permissão para a realização da pesquisa; explanação dos objetivos da pesquisa, a escolha dos sujeitos da pesquisa, a coletas dos dados.

Primeiramente, houve uma conversa sobre dois tipos de personagens, Mulan e Cinderela e as diferenças entre elas, contando a história destas personagens. Logo após a conversa, pediuse que as alunas desenhassem a personagem que mais gostassem de ouvir a história, ou se identificassem mais com a seguinte pergunta: "Qual personagem você se sente representada?".

Logo após a aplicação do procedimento para as duas turmas, recolheu-se os desenhos e ao longo da entrevista, foi anotado o que a criança relatava. Por meio das falas das crianças conseguiu-se compreender a interferência das personagens "modernas" como novos exemplos para as crianças. Também se percebeu a associação do pensamento das crianças de diferentes 
idades e gêneros, assim como, avaliar se essa influência é positiva na vida de cada criança. Nesta análise serão citados e estudados alguns desenhos que foram mais significativos e que representam o pensamento da maioria das crianças.

O estudo foi realizado em um colégio particular de Resende, na Região Sul Fluminense do Rio de Janeiro. A pesquisadora atua neste estabelecimento de ensino e após autorização da direção, o estudo foi aplicado.

Neste trabalho foram escolhidas aleatoriamente alunas do segundo ano e do quinto ano do Ensino Fundamental, incluindo todas as meninas das duas turmas. Participaram da pesquisa num total de 27 alunas, entre 8 e 11 anos, sendo 12 meninas do segundo ano e 15 do quinto ano e 10 docentes do colégio.

Foi utilizada entrevista não estrutura com as crianças para que relatassem sobre seus desenhos. A entrevista é um procedimento de coleta de informações, utilizado pelo pesquisador que segundo Marconi e Lakatos (2008) para orientar o pesquisador no campo.

Durante essa pesquisa, um das alunas entrevistadas (A. J. , de 7 anos) relatou em seu desenho que queria ser uma princesa como Cinderela, e quando questionada sobre o motivo, ela informa que queria realizar o sonho do príncipe, porque assim ele a amaria eternamente como no filme, já que a Cinderela foi uma "boa moça”, ele jamais deixaria de amá-la.

Como demonstrado nas imagens abaixo (Foto 1), algumas histórias foram contadas sem demonstrar preferência entre alguns personagens, histórias de personagens clássicas e das atuais. Depois de contar as histórias, houve o relato por escrito sobre o desenho das alunas, demonstrando qual era sua preferência, em qual personagem se espelharia segundo as histórias. A maioria das crianças escolheu as personagens atuais, afirmando que são mais ativas, correm atrás do que querem e uma fala me chamou muito a atenção, quando uma aluna diz que "nenhuma princesa é tão legal quanto à mãe dela", que é uma mulher que a criou sozinha, sem o apoio do pai ou uma figura masculina.

Com a fala dessa aluna, pode-se entender que o maior exemplo de todas essas meninas está realmente no dia a dia, pais, professores, amigos e todos que as cercam, sendo assim, é importância relatar o novo conceito de família, também trabalhado nos contos atuais, como Moana (2017), que mora com seu pai, sem ter uma figura materna por perto, e mesmo assim é considerado família por ela.

O conceito de família tradicional ser formado por pai, mãe e filhos é um estereótipo mantido pelos contos antigos, onde volta-se mais uma vez a atenção para a influência que causava na vida dos professores mais experientes, que tem uma visão de mundo diferente dos 
mais recentes, pois eram influenciados por contos extremamente machistas, onde o homem era o centro, e a mulher fazia o que fosse para conquistá-lo.

Aprofundando a fala da aluna, pode-se entender o contexto histórico social que cerca esta menina vive, já que são sensibilizados a seguirem exemplos que vivenciam, que estão presentes na famílias, nos hábitos e costumes e nas crenças religiosas e quando o assunto é autonomia de suas filhas, por receio que algo desagradável ou que elas se desapontem com alguma descoberta, por isto, é tão grande o cuidado em abundância, é o momento que alguns pais têm dificuldade de mostrar uma sociedade real, para protege-las dos perigos do caminho.

Esses são alguns relatos das alunas do quinto ano do Ensino Fundamental I, onde numa turma que contém dezoito meninas, sua maioria demonstrou uma visão feminista nas escolhas e nos motivos dos relatos:

Figura 1 - Desenho feito por uma aluna da personagem Mulan

Fonte: Acervo da Autora.

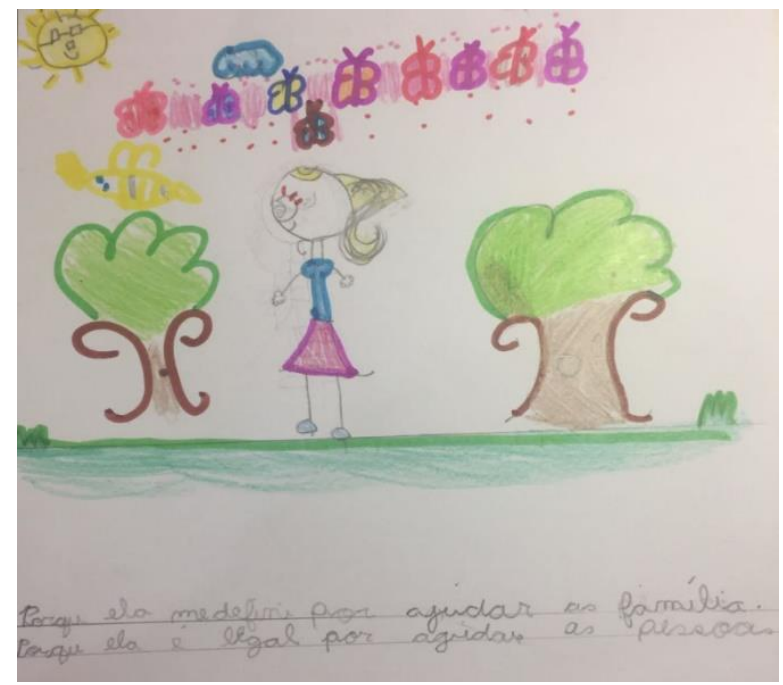

Na Foto 1 a aluna diz o porquê da escolha de personagem Mulan: "Porque ela me define por ajudar as famílias. Porque ela é legal por ajudar às pessoas", entende-se que o foco da personagem condiz com o mesmo que o seu; ajudar às pessoas. A aluna se vê nas atitudes de Mulan.

Figura 2 - Desenho feito por uma aluna da personagem Valente. 


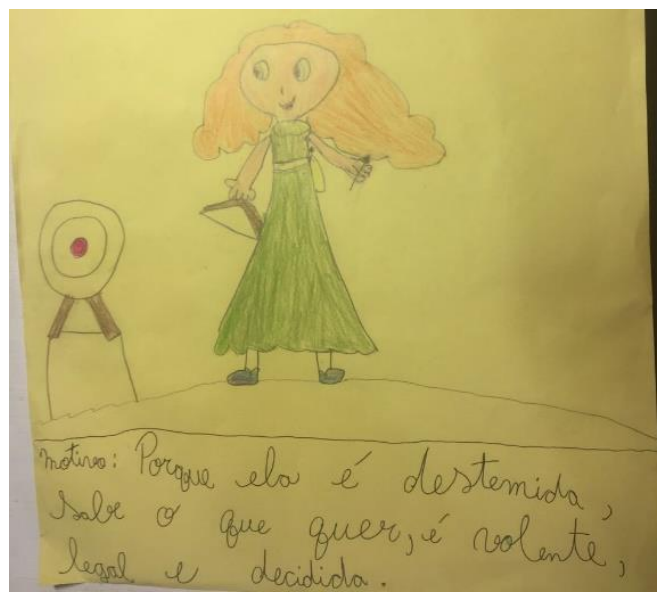

Fonte: Acervo da Autora.

Na Foto 2, quando a aluna I.C. diz "Merida, porque ela é destemida, sabe o que quer, é valente, legal e decidida.", também é notório o quanto a personagem influencia na escolha desta aluna, já que para escolher sua representação social, ela deve condizer com o que cada pessoa acredita.

Figura 3 - Desenho feito por uma aluna da personagem Moana.

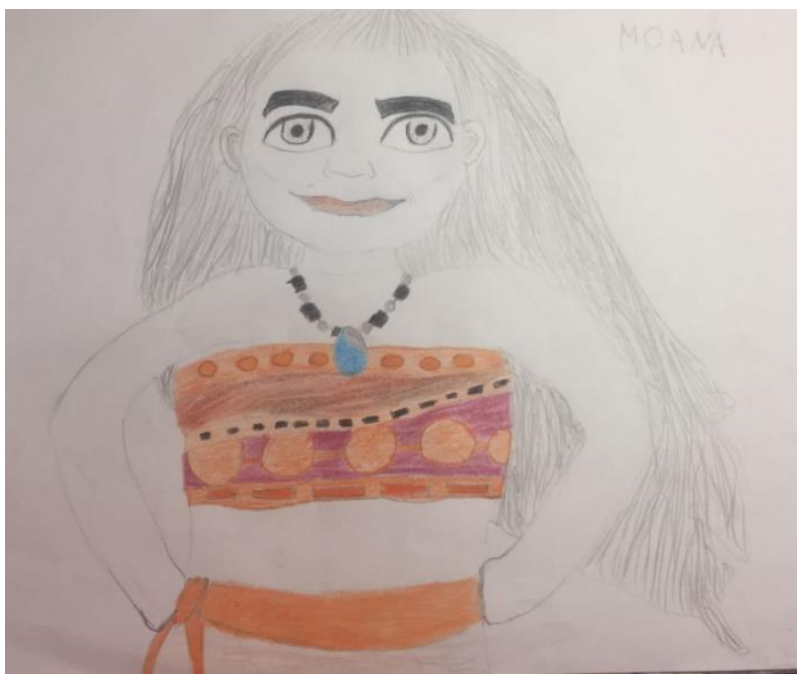

Fonte: Acervo da Autora.

Na Foto 3, quando a aluna C. C. diz "Moana, eu adoro a Moana, porque ela não quer um príncipe, ela quer só ajudar seu pai, eu também iria querer isso, porque ele me ajuda muito.”, compreende-se que a personagem citada referencia-se a família, remetendo a sua própria família. Também demonstra essa mudança de amor romântico que começa a se ausentar nos filmes, dando lugar ao amor familiar. 
Figura 4 - Desenho feito por uma aluna da personagem Valente.

Fonte: Acervo da Autora.

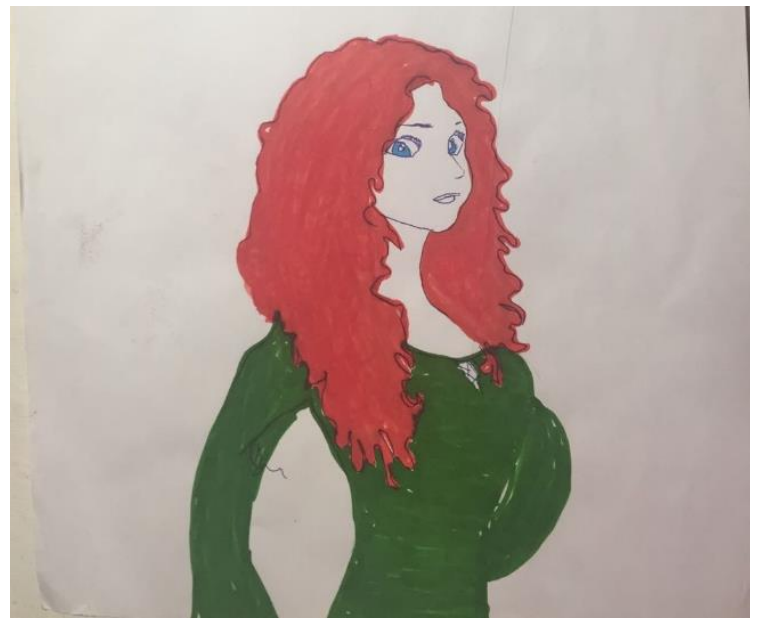

Na Foto 4, o relato não difere muito dos outros. Quando a aluna diz “ Merida. Ela é corajosa, valente e não desiste", traz-se à realidade o fato de que as personagens estão deixando de serem postas em segundo plano e realmente se tornando o personagem principal dos seus filmes.

Como pode-se observar, as justificativas são sempre voltadas à questão do altruísmo e amor ao próximo, de forma com que faça que essas alunas que participaram da pesquisa estejam realmente entendendo que essa mudança social vem de fato afetando o comportamento e ideologia das pessoas, como antigamente eram valorizados somente personagens de um certo tipo e hoje essa gama de oportunidades e opções faz com que aumente o número de pessoas que se sentem representadas socialmente pela personagem.

Esta é mais uma evidência de que meninas com idades mais avançadas entendem de outra forma o contexto passado em novos filmes da Disney, que sugerem que o amor ao próximo é mais importante que o amor romântico e que o mundo ideal não é somente um bom casamento e filhos, mas sim aquele, em que uma família luta pela outra. Essa visão mais ampla da sociedade faz com que essas meninas tendem a compreender quais os seus direitos e deveres e que são extremamente capazes de impor suas opiniões e vontades perante algumas situações.

Durante a aplicação do trabalho, as falas de algumas meninas chamaram atenção, pois sempre comentavam sobre suas preferências e segue algumas falas como: "Eu adorava a Branca de Neve, mas depois que teve a Moana... Ela é muito mais interessante"! (M.G, 11 anos), a outra aluna "Eu gosto da Frozen. Ela não usa rosa e nem eu." (M. 11 anos) e para completar "A Rapunzel é muito chata. Ela passa o dia inteiro esperando um homem acordar ela. Nem parece que ela tem perna para andar!" (P. 11 anos). Pode-se notar que algumas dessas meninas tinham 
plena ciência sobre o que estavam escolhendo, sempre pontuando a questão de "empoderamento", onde trazem a valorização da mulher e o conteúdo igualitário. Mesmo que por vezes ainda seguem padrões de uma sociedade com pouca mudança, elas têm plena ciência de que existem outras escolhas e estão apenas apontando que há uma sociedade em mudança.

Também é necessário ressaltar sobre àquelas que se identificam com as personagens mais tradicionais. Aquelas que foram criadas baseadas na sociedade da época, onde as personagens tinham quase sempre as mesmas características físicas, corpo magro, pele branca, cabelos e maquiagens impecáveis.

Figura 5 - Desenho feito por uma aluna da personagem Cinderela.

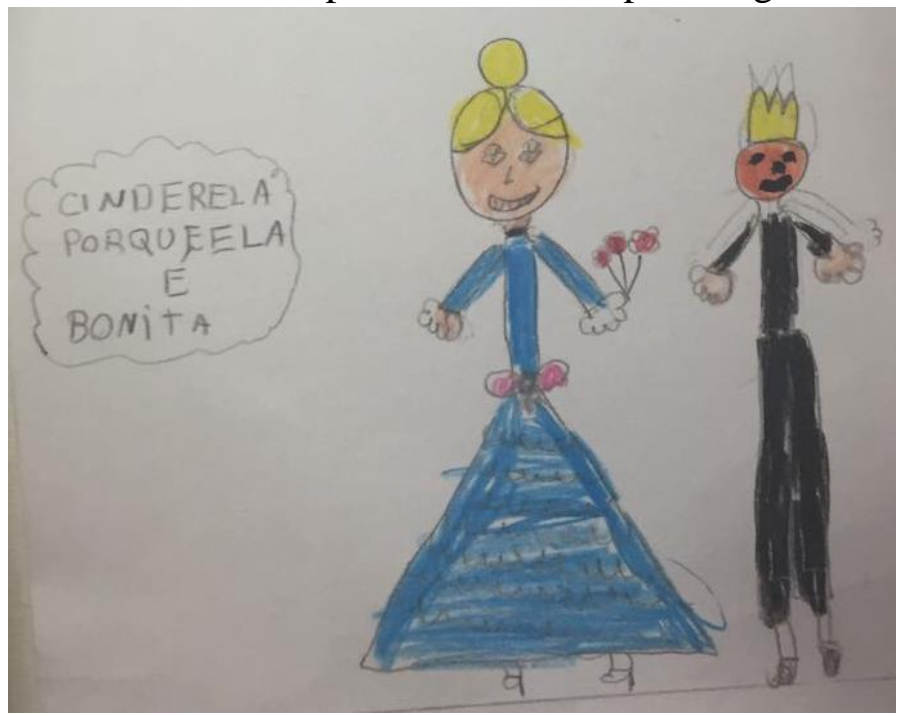

Fonte: Acervo da Autora.

Como na análise das fotos anteriores, observa-se que quando a aluna P.T. relata: "Cinderela: Porque ela é bonita", como é uma aluna mais nova, entende-se que as pessoas mais jovens tem mais dificuldade de discernir as informações mais complexas contidas nos filmes de tais personagens e também porque muitas vezes se recebe informações sem questionamentos.

Figura 6 - Desenho feito por uma aluna da personagem Rapunzel 


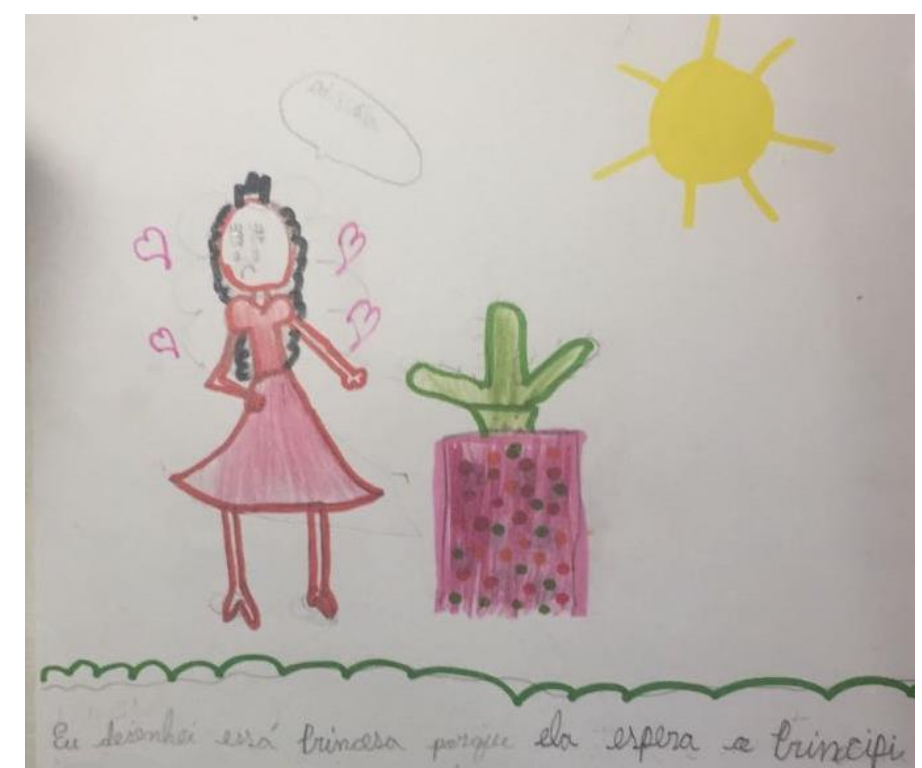

Fonte: Acervo da Autora.

A aluna F.M. comenta: "Eu desenhei essa princesa porque ela espera o príncipe", também é compreensível que essa aluna, ainda muito jovem sofre pouca influência das novas personagens, já que pode haver uma certa dificuldade de absorção de conteúdo mais complexo existentes nos novos filme, mais uma vez a falta de questionamentos sobre as personagens.

Figura 7 - Desenho feito por uma aluna da personagem Rapunzel.

Fonte: Acervo da Autora.

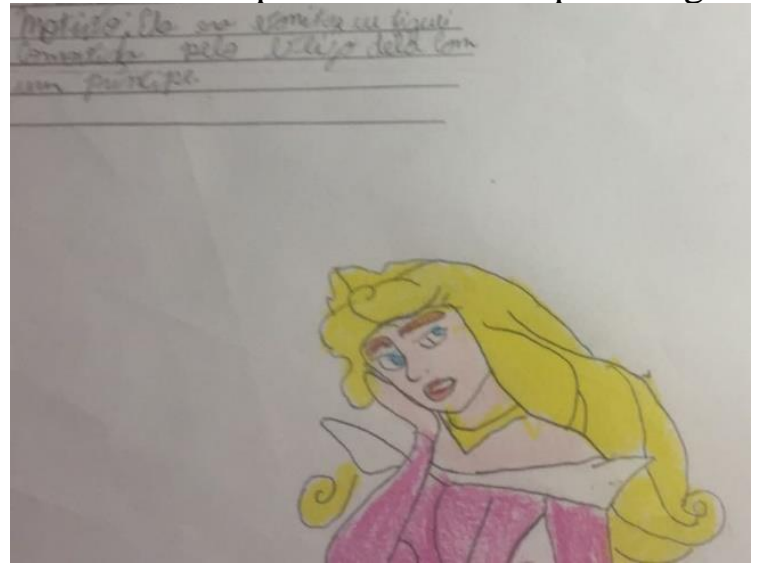

Na Foto 5, entende-se que quando a aluna O.P. comenta "Aurora (Rapunzel): Ela era bonita. Eu fiquei comovida com o beijo dela com o príncipe”, demonstra-se o quando esse passivismo dessa personagem é nítido em seu filme, fazendo com que a personagem, elenco principal fique em segundo plano.

Quando as meninas destacam somente a beleza das princesas, consegue-se entender que todo esse padrão estético é ainda muito impactante na vida delas, pois como o último relato, querer "ser magra, loira e de olho azul" igual à Rapunzel, ainda é a representatividade de uma Temas em Educ. e Saúde, Araraquara, v. 15, n. 1, p. 46-71, jan./jun., 2019. 
sociedade movida à beleza e deve-se repensar se esta é a melhor opção para ser seguida. Deixar com que as meninas façam suas próprias escolhas é o mais importante, porém auxiliá-las neste processo é essencial, já que é o que é difundido, é uma abordagem feminista dos contos atuais; tornar meninas pensantes e atuantes na sociedade.

Esse tipo de conto com o feminismo em sua subjetividade é importante para as meninas que estão começando sua vida social, como as meninas da quinta série para que elas entendam seu papel numa sociedade onde mesmo com tantas mudanças prós feminismo, ainda há resquícios do machismo evidente. Por isso devem compreender o seu lugar social e não deixar com que o preconceito por seu sexo as atinja ou as diminua.

Como expõe Sarmento (2005), as culturas infantis são marcadas pela interação, reiteração, ludicidade e fantasia, por outra ordem do tempo, pelas brincadeiras e pelo imaginário.

Com a criação de novas personagens para o universo infantil, pode-se entender que minorias que antes não eram valorizadas passam a ter destaques como princesas negras, com cabelos encaracolados, ruivos entre outros. Essa visibilidade vem não só pela característica física, mas como Moana (2017) que atrai a atenção para Tribo dos Motunui, e para a mitologia das tribos da Polinésia. Ou seja, essa geração de novas personagens não muda só o estereótipo corporal, mas traz consigo a cultura abrangente mundial de locais que talvez não tem tanto destaque.

\section{Reinventando as personagens clássicas}

Ao voltar-se para o questionamento sobre quem influencia quem; a Disney ou a sociedade, mais uma vez se registra que ambos caminham juntos. Algumas produtoras como a Disney vêm regravando e reinventando algumas de suas personagens clássicas, como se tivessem se readequando à sociedade de forma que possa agradar e trazer uma mensagem, sem retirar o elemento principal dos filmes: a mulher.

Para não perder público, a influência da mídia funciona mais uma vez de forma ágil para que as personagens não sejam deixadas para traz e esquecidas, substituídas por outras, mas sim voltem a fazer sucesso com uma forma atual de mensagem contida nos filmes e histórias. Graças ao crescimento do movimento feminista nas mídias sociais, essa regravação tem causado muita comoção no público, principalmente o infantil. As crianças esperam por histórias que as encorajam a buscar pelos seus sonhos e que não precisem de outras pessoas para "salvá-las". 
Figura 8 - Cinderela 1950 X 2015

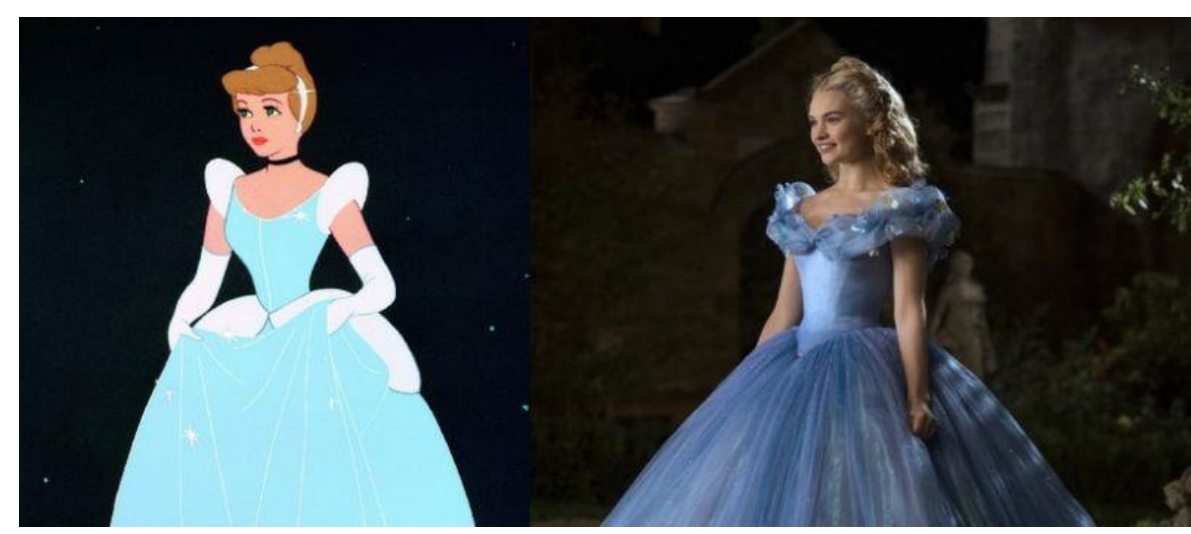

Fonte: https://www.vix.com/pt/cinema/559955/princesas-da-disney-se-transformaram-para-detonaralph-2-compare-o-antes-e-depois. Acesso em: 11 jan. 2019.

As duas personagens ainda mantêm o padrão de beleza. São magras, loiras e muito educadas. A diferença começa em 1950, quando a Cinderela era considerada uma personagem frágil, que necessitava de cuidados a todo momento e precisou ser salva por um homem, quando se parte da premissa, que seu sonho ainda era o casamento. Já em 2015, vê-se uma Cinderela mais libertária, que segue o ideário da mãe falecida “Seja corajosa e gentil”, colocando a família em primeiro lugar e não é posta como vítima, salvando-se sozinha, sem esperar por ajuda. Um fato a comentar é que o casamento da Cinderela de 2015 é uma consequência, e não o objetivo principal do filme.

Figura 9 - A Bela Adormecida 1959 X Malévola 2014

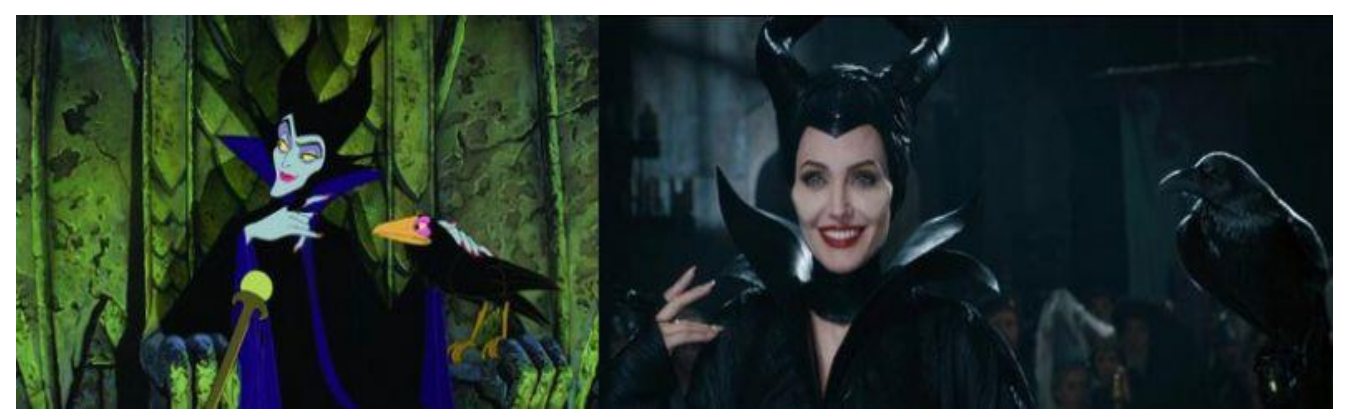

Fonte: https://www.vix.com/pt/cinema/559955/princesas-da-disney-se-transformaram-para-detonaralph-2-compare-o-antes-e-depois. Acesso em: 10 jan. 2019.

São trazidas duas obras diferentes, mas inspiradas no mesmo conto. O filme A Bela Adormecida (1959) nos relata sobre a vida da frágil Aurora, que passa a animação inteira como personagem secundária do seu próprio filme. A animação nos traz a ideia de mais uma vez uma mulher que espera ser salva pelo homem, dessa vez o beijo de amor verdadeiro quem salva a Aurora do seu sono profundo. Nessa animação, Malévola é a vilã que prende Aurora com um 
feitiço, quando Malévola foi excluída do batizado da pequena Aurora, o que causa repulsão na vilã e a faz agir desta forma. Em Malévola (2014), a história é contada pelo ponto de vista da vilã, que no fim do filme se revela a verdadeira mocinha, preocupada com Aurora. Em Malévola (2014), ainda é usado o beijo de amor verdadeiro, mas a grande diferença é que o beijo é dado por Malévola, que salva Aurora do seu sono profundo, mesmo depois do príncipe a ter beijado. O que nos traz a ideia de que o amor verdadeiro não é só o amor romântico entre duas pessoas, mas pode ser qualquer tipo de amor.

Os filmes atuais, ou regravações ultimamente tem como foco todo tipo de público, não somente o infantil, em que se pode observar que as pessoas em geral estão acompanhando mais os personagens e desenvolvendo afeto por eles. Então, essa influência deixa de ser somente sobre as crianças e começa a ser sobre todos os consumidores dos produtos.

\section{Considerações finais}

Com a pesquisa apresentada, conclui-se que quanto mais velhos, ou nas séries mais avançadas, essa influência aumenta, fazendo com que as turmas mais novas, como a do segundo ano, em sua maioria escolhendo a princesa clássica, mostra que a idade interfere sim no entendimento dos clássicos da Disney. Do mesmo modo as crianças mais velhas, como a turma do quinto ano em sua maioria optou pela princesa atual, referindo-se a ela como "guerreira", "mulher de hoje" e "como minha mãe"

As histórias contadas, tanto no segundo ano quanto no quinto ano, foram contadas na forma interpretação livre, sem o objetivo de interferir nas escolhas feitas pelos alunos, assim, eles conseguiam falar por si, não somente para agradar a professora.

Fui muito surpreendida quanto às palavras que algumas meninas relataram em seus discursos sobre o motivo de suas escolhas, pois quando o discurso é "Quero me casar com um príncipe" percebemos claramente a influência dessas princesas e contos clássicos para que faça com que meninas de idade entre 8 a 12 pensem tão diferente, tenham reflexões às vezes opostas sobre o tema e reparem em detalhes que são únicos de cada história.

Em relação às conversas com as professoras, essa observação citada assim também é bastante evidente, já que os professores mais experientes entendem que as princesas clássicas são um melhor exemplo para as meninas, já que as atuais usam armas e muitas vezes um "discurso feminista ativista" para convencer meninas a agirem de forma violenta. 
É necessário comentar também sobre o fato de que esses professores tiveram sua formação desse modo, aprenderam que esse era o certo e assim passam não somente sua vida acadêmica, mas sua vida social com esse pensamento conservador. Mesmo sendo criados e ensinados dessa forma, entende-se que cada vez o assunto sobre feminismo e sexualidade entram em pauta, portanto, se manter livres de ideias preconcebidas para compreender todos os lados, e seguir sem preconceito.

Em contraponto, os professores mais novos acreditam que esse "discurso feminista ativista" possa ajudar algumas meninas a serem mais empoderadas, a saberem rebater quando não concordarem e ter um discurso mais aberto sobre qualquer tema em suas residências.

Esses professores afirmaram de modo menos impositivo, que deve-se aceitar as mudanças ocorridas no entorno, entendendo que as crianças estão se reconhecendo no mundo cada vez mais cedo e deve-se dar o "apoio emocionalmente social", citado por um professor dessas crianças.

Essa afirmação dos professores experientes só nos remete ao fato de que essa imposição de histórias que deixam a mulher em segundo plano precisa ser repensada, pois esse era um fato aceito como normal nas famílias tradicionais.

Tais contos atuais, com personagens que lutam pelo que querem são comparados à nova formação de família, que deixa todo aquele tradicionalismo de pai, mãe e filhos e demonstra que as famílias não precisam ter formações iguais.

Mais uma vez a mídia busca um jeito de incentivar e/ou influenciar os consumidores quando renova e refaz os filmes de uma forma, que são aceitos nesta sociedade contemporânea. Assim, consegue-se entender que a mídia influencia as gerações futuras e depende de como os professores vão lidar com estas formas de consumo e ajudar as alunas no entendimento dos seus direitos e de como driblar situações fora de sua zona de conforto.

\section{REFERÊNCIAS}

ARIÉS, P. História social da criança e da família. 2.ed. Rio de Janeiro: Guanabara, 1973. BRANCA de neve. Produção de Walt Disney. Estados Unidos: Disney, 1937. 1 rolo de filme. CINDERELA. Produção de Marc Davis. Estados Unidos: Disney, 1950. 1 rolo de filme. les représentations intériorisées par les enfants. Tradução: Moacir Palmeira. Paris: Delachaux \& Niestlé, 1986. 
DE MAUSE, L. História da Infância. Madri, Alianza Universid: 1991.

FROZEN. Produção de Peter Del Vecho. Estados Unidos: Disney, 2013. 1 dvd.

HOMEM aranha. Produção de Laura Ziskin. Estados Unidos: Sony, 2012. 1 dvd.

JODELET, D. O movimento de retorno ao sujeito e a abordagem das representações sociais. Sociedade e Estado, Brasília, v. 24, n. 3, p. 679-712, set./dez. 2009.

LA TAILLE, Y. A publicidade dirigida ao público infantil: considerações psicológicas. In: Contribuição da psicologia para o fim da publicidade dirigida à criança. Conselho Federal de Psicologia: Brasília, DF, 2008.

LAKATOS, E. M.; MARCONI, M. A. Metodologia científica. ed. São Paulo: Atlas, 2008.

LEVIN, E. A infância em cena: constituição do sujeito e desenvolvimento psicomotor.

Petrópolis, Rio de janeiro: Vozes, 1997.

LINS. B. A.; MACHADO, B.F; ESCOURA. M. Diferentes, não desiguais: a questão de gênero na escola. São Paulo: Reviravolta, 2016.

MALÉVOLA. Produção de Joe Roth. Estados Unidos: Disney, 2017. 1 dvd.

MATTAR, F. N. Pesquisa de marketing. 3.ed. São Paulo: Atlas, 2001.

MOANA. Produção de Walt Disney Studio. Estados Unidos: Disney, 2014. 1 dvd.

MOSCOVICI, S. Representações Sociais: investigações em psicologia social. Editado em inglês por Gerard Duveen; traduzido do inglês por Pedrinho A. Guareschi. 7. ed. Petrópolis, RJ: Vozes, 2010.

MULAN. Produção de Pam Coats. Estados Unidos: Disney, 1998. 1 VHS.

MULHER maravilha. Produção de Charles Roven. Estados Unidos, 2017. 1 dvd.

NEIL, G. Walt Disney: o triunfo da imaginação americana. Novo Século.

NARODOWSKI, M. Infância e poder: a confrontação da pedagogia moderna. Tese de doutorado em educação. Universidade Estadual de Campinas, 1993.

PIERRE-PUYSEGUR, M. A.; CORROYER, D. Les représentations du sistéme pénal chez les enfants de six à dix ans. Enfance, 40 (3), 1997.

RAPUNZEL. Produção de Roy Colin. Estados Unidos: Disney, 1962. 1 rolo de filme.

ROCHA, R. C. L. História da infância: reflexões acerca de algumas concepções correntes. Disponível em: https://pt.scribd.com/doc/28155072/HISTORIA-DA-INFANCIAREFLEXOES-ACERCA-DE-ALGUMAS-CONCEPCOES-CORRENTES. Acesso em: 10 jan. 2019. 
SAMPAIO, M. F. História do rádio e da televisão no Brasil e no mundo. Rio de Janeiro: Achiamé, 1984.

SILVA, T. T. Documentos de identidade: uma introdução às teorias do currículo. Belo Horizonte: Autêntica, 1999.

SHIMIZU, A. M. O potencial de influência da mídia na construção de representações de aspectos socio-morais. Disponível em:

http://faef.revista.inf.br/imagens_arquivos/arquivos_destaque/wiHJlohM1xY2VHg_2013-430-11-48-31.pdf. Acesso em: 12 ago. 2018.

STRAUBHAAR, J.; LAROSE, R. Comunicação, mídia e tecnologia. São Paulo: Pioneira Thomson Learning, 2004.

TEIXEIRA, E. Contadores de histórias encantam gerações e incentivam a leitura.

Disponível em: https://www.correiobraziliense.com.br/app/noticia/diversao-e-

arte/2010/06/22/interna_diversao_arte,198791/contadores-de-historias-encantam-geracoes-eincentivam-a-leitura.shtml. Acesso em: 06 jul. 2018.

VALENTE. Produção de Katherine Serafian. Estados Unidos: Disney, 2012. 1 dvd.

X-MEN. Produção de Lauren Shuler Donner. Estados Unidos: Century Fox, 1994. 1 hq.

CORREIO BRAZIELIENSE. Contadores de histórias encantam gerações e incentivam a leitura. Correio Brasiliense. Disponível em:

https://www.correiobraziliense.com.br/app/noticia/diversao-e-

arte/2010/06/22/interna_diversao_arte,198791/contadores-de-historias-encantam-geracoes-eincentivam-a-leitura.shtml. Acesso em: 29 maio 2018.

PORTAL EDUCAÇÃO. Como a criança era vista e tratada desde a época medieval até o século XX. Portal Educação. Disponível em:

https://www.portaleducacao.com.br/conteudo/artigos/educacao/como-a-crianca-era-vista-etratada-desde-a-epoca-medieva-ate-o-seculo-xx/26547. Acesso em: 29 maio 2018.

YIN, R.K. Estudo de caso: planejamento e métodos. 3ed. Porto Alegre: Bookman, 2005.

\section{Como referenciar este artigo}

ESTEVES, Rosa Maria Maia Gouvêa; DUARTE, Amanda Ribeiro. A representação da imagem da mulher nas personagens infantis. Temas em Educ. e Saúde, Araraquara, v. 15, n. 1, p. 4671, jan./jun., 2019. e-ISSN 2526-3471. DOI: 10.26673/tes.v15i1.12770

Submetido em: 10/01/2019

Aprovado em: 30/04/2019 